\title{
Prevalence of Cardiovascular Diseases in a Tertiary Care Teaching Hospital
}

\author{
Chandana Naliganti', Chandrasekhar Valupadas*2, Raghuram Rao Akkinepally³ \\ ${ }^{1}$ Department of Pharmaceutical Sciences, University College of Pharmaceutical Sciences, Kakatiya University, Warangal, Telangana, \\ INDIA. \\ 2Department of General Medicine, Kakatiya Medical College/ Mahatma Gandhi Memorial Hospital, Warangal, Telangana, INDIA. \\ ${ }^{3}$ Department of Pharmaceutical Chemistry, University College of Pharmaceutical Sciences, Kakatiya University, Warangal, Telangana, \\ INDIA.
}

\begin{abstract}
Background: Cardiovascular disease (CVD) comprises the most prevalent serious disorders in the developed and developing nations. Epidemiological studies have played an important part in the elucidation of predisposing factors for CVD and opportunities for prevention and treatment. The present study is designed retrospectively to focus on prevalence of various CVD and causes of mortality in patients admitted to cardiology unit. Materials and Methods: A retrospective epidemiological study was conducted in the Intensive Cardiac Care Unit (ICCU) of a tertiary care teaching hospital where the data was collected from January, 2013 to June, 2015 (2.5 years). The study population includes all the patients admitted to ICCU with various symptoms of CVDs. The demographic and clinical data was obtained from the records and the analysis was performed. Results: A total of 6,307 patients were admitted in ICCU with an average age of 52 years in which majority was men (58.33\%). The study indicates coronary heart disease (CHD) $(67.06 \%)$ was most prevalent among other CVDs and non-CVDs. A total of 592 $(9.12 \%)$ deaths were noted during the study period where mortality rate was high in females $(11.26 \%)$. Acute myocardial infarction (AMI) and heart failure accounted for major deaths in ICCU. Conclusion: The study observed the significant prevalence of various CVD. Based on the results we hypothesize that serological studies will be necessary to identify the specific underlying aetiology/infectious pathogenesis leading to death and prospective observational study will yield significant strength to epidemiological studies respectively.
\end{abstract}

Key words: Cardiovascular diseases, Prevalence, Mortality, Epidemiological studies.

\section{INTRODUCTION}

Cardiovascular disease (CVD) is a high priority health issue in the community. A large proportion of those dying or utilising both acute and other health care support and services are in fact suffering from various CVDs or co morbidities associated with them. Eventually, lifestyles are also affected by it, which resulted in disability and/or deterioration in quality of life. ${ }^{1}$ Importantly, it remains the foremost cause of preventable inpatient mortality globally. Epidemiological studies have played an important role in the elucidation of predisposing factors for CVD and opportunities for prevention and treatment.
According to India Council of Medical Research, by 2020 CVDs will be the largest cause of mortality and disability in which 2.6 millions are predicted to die due to coronary heart disease which constitutes $54.1 \%$ of all CVD deaths ${ }^{2}$ in India. It is pathetic to understand that half of these deaths are likely to occur in young and middle aged individuals (30-69 years).

According to Global Burden of Disease (GBD) study, $52 \%$ of CVD deaths occur below the age of 70 years in India as compared to $23 \%$ in established market economies resulting in an intense adverse impact on its economy as well as society. ${ }^{3}$ An increase in the prevalence of risk factors like hypertension; dyslipidemia; dia-
DOI: 10.5530/ijopp.9.4.1

Address for correspondence: Dr. Chandrasekhar Valupadas, M.D.,

Department of General Medicine, Kakatiya Medical College/ Mahatma Gandhi Memorial

Hospital, Warangal, Telangana, INDIA.

Phone no: 09346950050; Fax: 0870-2446868

E-mail: drvcmed67@gmail.com

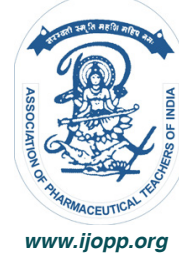


betes; overweight; physical inactivity and tobacco use are widely perceived as the contributing factors for the growing burden of CVDs. It is a remarkable area where major health gains can be made through the implementation of primary care interventions and basic public health measures targeting diet, lifestyles and the environment. ${ }^{4}$

World Health Organization (WHO) recently reported that CVDs are the primary cause of death globally among non-communicable diseases annually. An estimated 17.5 million people died from CVDs in 2012, representing 31\% of all global deaths. Among these deaths, an estimated 7.4 million were due to coronary heart disease and 6.7 million were due to stroke. ${ }^{5}$ In 2014, about $26 \%$ of people died with CVDs in India. ${ }^{6}$ Interestingly, WHO stated that projection of number of deaths due to cardiovascular disease will be $45.59 \%$ world-wide and $44.11 \%$ in south-east Asia by 2015 and $42.95 \%$ world-wide and $43.59 \%$ in south-east Asia by $2030 .^{7}$

In order to formulate national policies for the prevention and control of CVDs, we require nationally representative data collected through standardized techniques. In many regions in Telangana state the data is not compiled together.

\section{MATERIALS AND METHODS}

This is an epidemiological study conducted retrospectively at the ICCU of a tertiary care teaching hospital i.e., Mahatma Gandhi Memorial Hospital, Warangal, Telangana, India, which is a 1200 bedded multidisciplinary government hospital from January, 2013 to June, 2015 (2.5 years). All the patients admitted to cardiology unit were included in the study who was suffering from various CVDs. Patients' demographic and diagnostic data between 14 to 90 years of age were collected from the patient

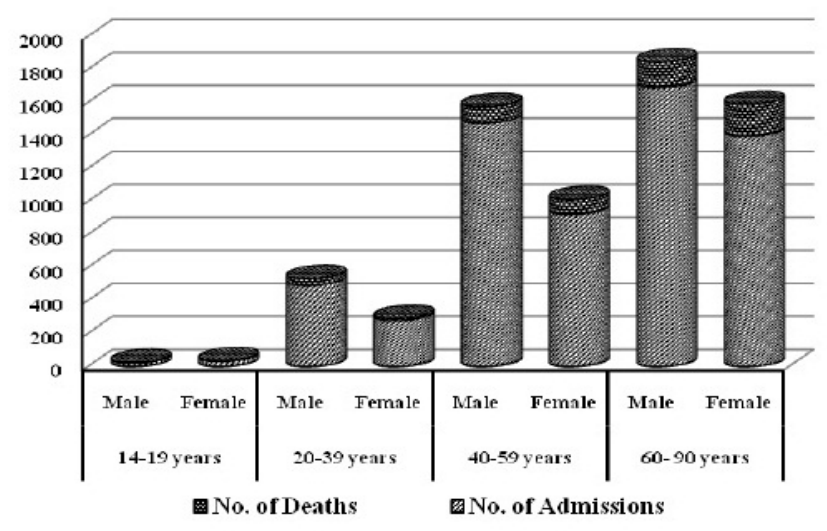

Figure 1: Age \& Gender-based distribution of study population in ICCU. records in ICCU and descriptive analysis was performed.

\section{RESULTS}

A total of 6,307 patients were admitted during the study period with various symptoms of CVDs. Majority of study population admitted to ICCU were male patients $(58.33 \%)$. Total number of death cases reported were 592, in which majority were female (11.26\%) (Figure 1).

Rate of admission was found to be constantly increased with aging in both males and females; rate of mortality was found to be high in male adolescents (14-19 years) and middle aged (40-59 years) and elderly (60-90 years) female patients (Table 1$)$.

The number of admissions were increased during the year 2015 when compared to 2014 and 2013 (Figure 2); number of deaths were decreased in the year 2015 when compared to 2014 and 2013 (Figure 3).

The study depicts seasonal variation in the admissions, mostly in the month of June to September (38.8\%) in 2013; September to December (41.32\%) in 2014; January (18.84\%) and March (19.78\%) in 2015 and mortality in the month of July in 2013; August (16.77\%) and October (14.4\%) in 2014; June $(13.04 \%)$ in 2015.

Figure 4 illustrates the prevalence of various cardiovascular and non-cardiovascular diseases among the study population admitted to ICCU. Among them coronary heart disease $(67.06 \%)$ was found to be most prevalent CVD comparative to the others.

Table 2 represents the distribution of all the baseline characteristics of the study population. Both smoking and alcoholism were found to be predominant social risk factors. Regional distribution was high from Warangal city (85.19\%) and rest of population from surrounding areas.

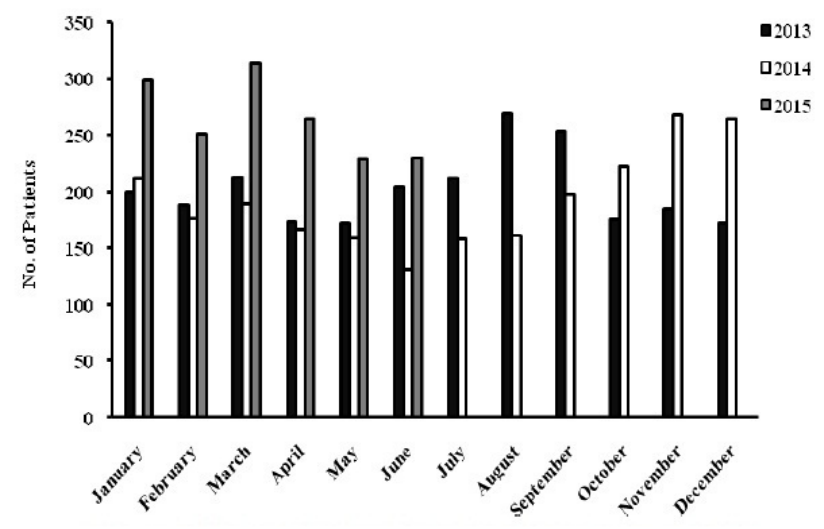

Figure 2: Month-wise Admissions of study population in ICCU. 
Table 1: Age and Gender-based distribution of study population in ICCU

\begin{tabular}{ccccccccc}
\hline & \multicolumn{2}{c}{$\mathbf{1 4 - 1 9}$ years } & \multicolumn{2}{c}{$\mathbf{2 0 - 3 9}$ years } & \multicolumn{2}{c}{$\mathbf{4 0 - 5 9}$ years } & \multicolumn{2}{c}{$\mathbf{6 0 - 9 0}$ years } \\
\cline { 2 - 9 } & Male & Female & Male & Female & Male & Female & Male & Female \\
\hline Admissions (N=6307) & & & & & & & & \\
$\quad$ Frequency (N) & 20 & 30 & 493 & 278 & 1476 & 924 & 1690 & 1396 \\
$\quad$ Percent (\%) & 0.32 & 0.48 & 7.81 & 4.41 & 23.40 & 14.65 & 26.80 & 22.13 \\
Deaths (N=592) & & & & & & & & \\
$\quad$ Frequency (N) & 4 & 4 & 39 & 13 & 98 & 87 & 155 & 192 \\
$\quad$ Percent (\%) & 20 & 13.33 & 7.90 & 4.67 & 6.64 & 9.40 & 9.17 & 13.75 \\
\hline
\end{tabular}

Table 2: Baseline characterisitics of the study population

\begin{tabular}{|c|c|c|}
\hline Characteristic & $\begin{array}{c}\text { No. of } \\
\text { Population }\end{array}$ & Percent \\
\hline \multicolumn{3}{|l|}{ Gender Distribution ( $N=6307$ ) } \\
\hline Male & 3679 & 58.33 \\
\hline Female & 2628 & 42.67 \\
\hline \multicolumn{3}{|l|}{ Personal History $(\mathrm{N}=6307)$} \\
\hline Smoking & 788 & 12.5 \\
\hline Alcoholism & 987 & 15.65 \\
\hline Both Smoking and Alcoholism & 2560 & 40.6 \\
\hline Neither Smoking nor Alcoholism & 1972 & 31.25 \\
\hline \multicolumn{3}{|l|}{ Region (N=6307) } \\
\hline Warangal & 5373 & 85.19 \\
\hline Karimnagar & 680 & 10.78 \\
\hline Khammam & 114 & 1.81 \\
\hline Adilabad & 108 & 1.71 \\
\hline Nalgonda & 15 & 0.24 \\
\hline Hyderabad & 3 & 0.05 \\
\hline Nijamabad & 1 & 0.02 \\
\hline Medak & 3 & 0.05 \\
\hline Andhra Pradesh & 6 & 0.09 \\
\hline Tamil Nadu & 3 & 0.05 \\
\hline Maharashtra & 1 & 0.02 \\
\hline \multicolumn{3}{|l|}{ Outcome (N=6307) } \\
\hline Discharged & 5400 & 85.62 \\
\hline Left against medical advice & 315 & 4.99 \\
\hline Death & 592 & 9.39 \\
\hline \multicolumn{3}{|l|}{ Etiology of Deaths $(N=592)$} \\
\hline Only Heart Failure & 24 & 4.05 \\
\hline Heart Failure +1 co morbidity & 98 & 16.55 \\
\hline Heart Failure + 2 co morbidities & 48 & 8.11 \\
\hline Heart Failure +3 co morbidities & 25 & 4.22 \\
\hline Only Cardiac Arrhythmia & 10 & 1.69 \\
\hline $\begin{array}{l}\text { Cardiac Arrhythmia + } 1 \text { co } \\
\text { morbidity }\end{array}$ & 14 & 2.37 \\
\hline $\begin{array}{l}\text { Cardiac Arrhythmia + } 2 \text { co } \\
\text { morbidities }\end{array}$ & 11 & 1.86 \\
\hline $\begin{array}{l}\text { Cardiac Arrhythmia }+3 \text { co } \\
\text { morbidities }\end{array}$ & 3 & 0.51 \\
\hline
\end{tabular}

\begin{tabular}{|c|c|c|}
\hline Only Heart Block & 2 & 0.34 \\
\hline Heart block + 1 co morbidity & 7 & 1.18 \\
\hline Heart block +2 co morbidities & 2 & 0.34 \\
\hline Heart block + 3 co morbidities & 1 & 0.17 \\
\hline $\begin{array}{l}\text { Cardiogenic shock + } 1 \text { co } \\
\text { morbidity }\end{array}$ & 26 & 4.39 \\
\hline $\begin{array}{l}\text { Cardiogenic shock }+2 \text { co } \\
\text { morbidities }\end{array}$ & 12 & 2.03 \\
\hline $\begin{array}{l}\text { Cardiogenic shock }+3 \text { co } \\
\text { morbidities }\end{array}$ & 7 & 1.18 \\
\hline Only Myocardial Infarction & 202 & 34.12 \\
\hline $\begin{array}{l}\text { Myocardial Infarction + } 1 \text { co } \\
\text { morbidity }\end{array}$ & 43 & 7.26 \\
\hline $\begin{array}{l}\text { Myocardial Infarction + } 2 \text { co } \\
\text { morbidities }\end{array}$ & 16 & 2.7 \\
\hline Unstable Angina & 3 & 0.51 \\
\hline Infection & 2 & 0.34 \\
\hline Pericardial effusion & 6 & 1.01 \\
\hline Cardio-respiratory Disease & 13 & 2.2 \\
\hline Hepatorenal Syndrome & 1 & 0.17 \\
\hline Peripheral Vascular Disease & 2 & 0.34 \\
\hline Cerebrovascular Disease & 2 & 0.34 \\
\hline Respiratory Disease & 2 & 0.34 \\
\hline Casualty Deaths & 2 & 0.34 \\
\hline Not specified & 8 & 1.35 \\
\hline
\end{tabular}

Large proportions of patients are found to be discharged after the therapy was initiated and about $4.99 \%$ was found to be left prior to treatment against medical advice. About $87.16 \%$ of mortality occurred in middle aged (40-59 years) and elderly (60-90 years) population.

Graphically, Figure 5 enumerates the causes of death in the study population in which acute myocardial infarction (45\%) was found to be the major cause followed by heart failure (33\%) and other causes were least accounted. $59.8 \%$ of deaths were due to cumulative disease condition where the patient suffered from more than one illness and $40.2 \%$ were found to be due to single disease exposure. 


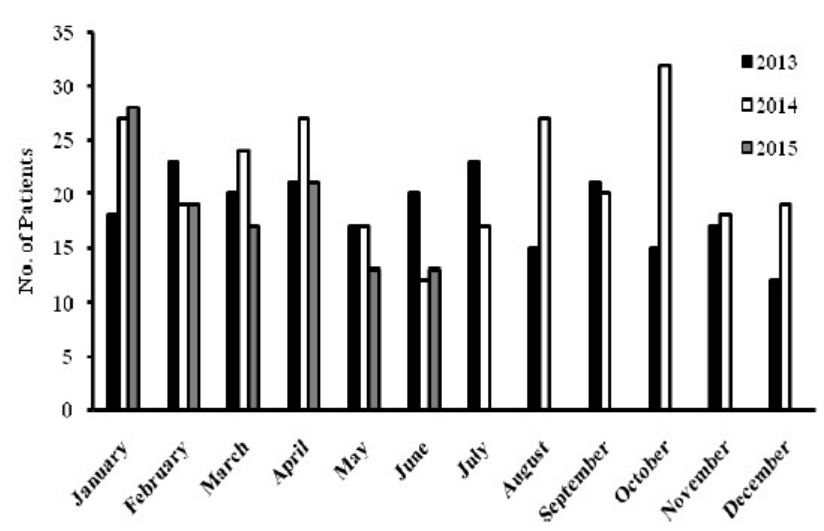

Figure 3: Month-wise Deaths of study population in ICCU.

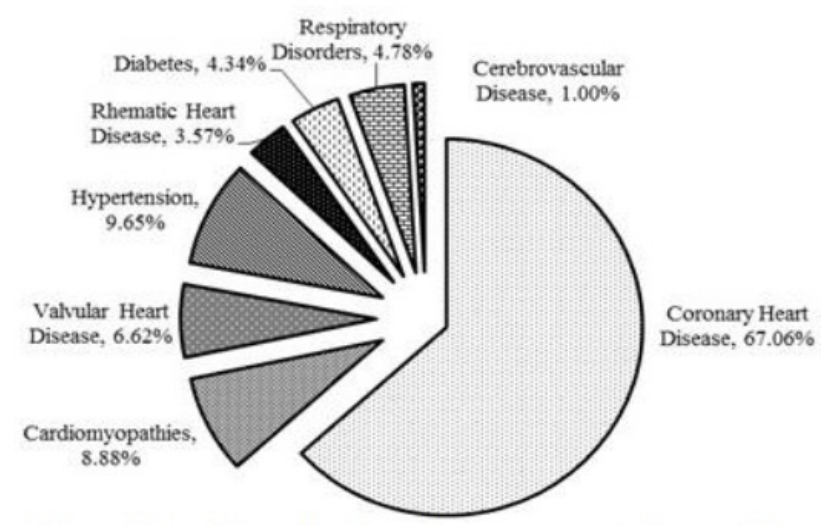

Figure 4: Prevalence of various diseases among study population.

\section{DISCUSSION}

In India, CVD is the largest cause of death and its prevalence increases with age. There is an increased necessity for identifying the people who at the risk of mortality. The present study shows the prevalence of CVDs was found to be high in males than females, which is in agreement with results demonstrated earlier in $2013 .{ }^{8}$ Most of the hospital admissions were above 40 years of age and the major cause was found to be coronary heart disease. Interestingly it is also supportive to the data provided by WHO $2014 .^{6}$

About $9.4 \%$ deaths were reported during the study period. It was found that risk of mortality is high in middle age and elderly patients with acute myocardial infarction and heart failure as major cause of death in the study population when compared to other causes. This finding is similar to the data provided by world health report. ${ }^{2}$ A study reported that the heart failure affects younger age group predominantly in India in 2010. ${ }^{9}$ However the results of the study show that heart failure is seen mostly in elder group above 50 years of age. Heart failure, cardiogenic shock, cardiac arrhythmias or heart block are

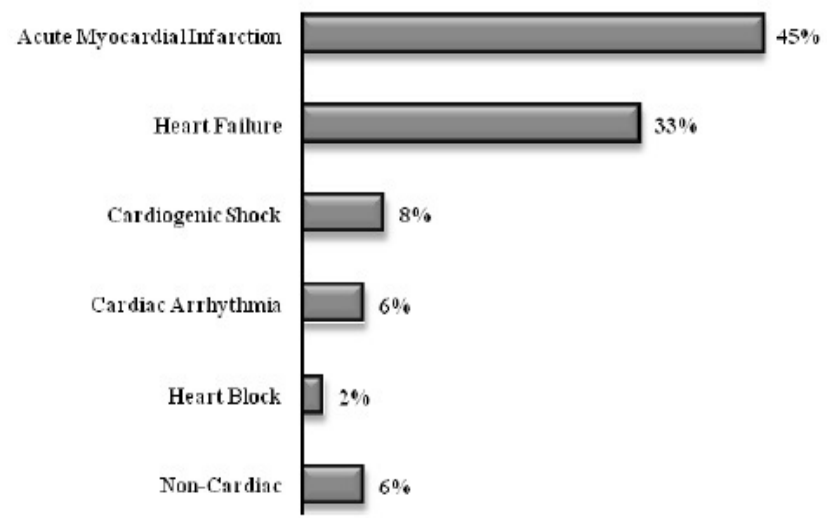

Figure 5: Etiology of deaths in ICCU.

the final pathways leading to death in patients diagnosed with any CVD. The study shows myocardial infarction as major cause of death but it is assumed that deaths have occurred with development of cardiogenic shock and cardiac arrhythmias.

We have observed that there is seasonal variation in the admissions and mortality in the study population which could be due to underlying coronary heart disease precipitated by infectious aetiology, probably cardio tropic viruses where lower temperature favours the growth, multiplication and transmission.

\section{CONCLUSION}

The study concludes that the prevalence of cardiovascular diseases was high in male patients and mortality rate was high in female patients. Association between development of CVD and age is found to be causal. Prospective studies have greater significance than retrospective ones which provide supplementary information to identify and update the burden of diseases; consequently to decrease the mortality by improvising the treatment options. Further research is required to identify true aetiology/pathogenesis behind mortality. Although studies have been conducted to assess CVD and its risk factor burden in many regions of India, the data was not compiled together.

\section{ACKNOWLEDGEMENT}

We thank the physicians in cardiac unit of MGM Hospital, Warangal for supporting the study. Our gratitude is extended to the Principal, University College of Pharmaceutical Sciences, Kakatiya University, Warangal, Telangana, India for assisting in the preparation of this manuscript. 


\section{CONFLICTS OF INTEREST}

All authors declared no conflicts of interest.

\section{ABBREVIATION USED}

CVD: Cardiovascular disease; GBD: Global Burden of Disease; WHO: World Health Organization; ICCU: Intensive Cardiac Care Unit/Intensive Coronary Care Unit; CHD: Coronary Heart Disease; AMI Acute Myocardial Infarction.

\section{REFERENCES}

1. Carol G, Ursula W. The Epidemiology of Cardiovascular Disease in the ACT. Department of Health and Community Care, Community Health Services, the Australian Bureau of Statistics, January 1997.

2. The Task Force Study on Coronary Heart Disease in India, 1994, Indian Council of Medical Research, Project. No. 1988-0608A.
3. Murray CJL, Lopez AD. Global mortality, disability and contribution of risk factors: Global Burden of Disease Study. Lancet. 1997:349(9063);1436-1442. http://dx.doi.org/10.1016/S0140-6736(96)07495-8.

4. Ajay VS, Ruby G, Jeemon P, Vivek C, Dorairaj P, Srinath KR. National Cardiovascular Disease Database. Resources National CVD database 2005Final Report.

5. World health Organization. (2015). Cardiovascular diseases: Fact sheet No. 317: 2015. Available from: URL: http://www.who.int/mediacentre/factsheets/ fs317/en/

6. World health Organization. (2014). Non-communicable Diseases Country Profiles 2014. Available from: URL: http://apps.who.int/iris/ bitstream/10665/128038/1/9789241507509_eng.pdf .

7. World health Organization. (2012). Projection of number of deaths 2012 Available from: URL: http://apps.who.int/gho/indicatorregistry/App_Main/view_ indicator.aspx?iid=36.

8. Rattan KC, Niamatullah, Arif Md. Nutritional status assessment and dietary intake of the cardiovascular disease patients. ARPN Journal of Agricultural and Biological Science. 2013;8(2):119-24.

9. Reddy S, Bahl AA, Talwar KK. Congestive heart failure in Indians: How do we prove diagnosis and management? Indian Journal of Medical Research. 2010;132(5):549-60 